
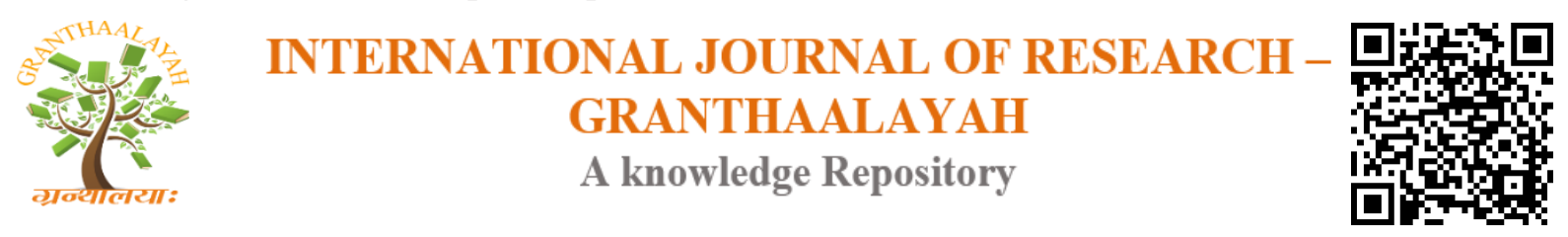

Management

\title{
ESTIMATING ATMOSPHERIC CARBON DIOXIDE EMISSIONS THRESHOLD FOR NIGERIA: A GUIDE FOR ENVIRONMENTAL POLICY
}

\author{
Aliyu Alhaji Jibrilla *1 \\ ${ }^{* 1}$ Department of Economics, Faculty of Social and Management Sciences, Adamawa State \\ University, Mubi, Nigeria
}

\begin{abstract}
This study empirically evaluates whether Green House Gases (GHGs) significantly increase with the rising population and urban growth in Nigeria. In addition, the study examine whether the energy demand also influences Nigerian contribution of global pollution emissions. The results of the Autoregressive Distributed Lag (ARDL) cointegration test indicated long-run and stable relationships among the variables. For affluence, we find evidence that, in the long run, domestic per capita income significantly increases carbon dioxide emissions and then falls after a certain extreme point, providing evidence of an inverted EKC hypothesis in Nigeria. The EKC finding was further supported by appropriate inverted $U$ test. The results also demonstrated that both urbanisation and population change do not have a long term effect on emissions; although urbanisation seems to significantly raise emissions in the short-run. Energy demand has been found to have a significantly positive elasticity effect on carbon dioxide emissions both in the longand short-run. The short-run Granger causality results indicate that, all variables make a short-run adjustment to correct any deviation from the long-run equilibrium. In addition, analysis of the error correction models reveals that all of the variables contribute to their stable long-run relationship.
\end{abstract}

Keywords: Urbanization; Energy Consumption; Economic Growth; Emissions; ARDL.

Cite This Article: Aliyu Alhaji Jibrilla. (2018). "ESTIMATING ATMOSPHERIC CARBON DIOXIDE EMISSIONS THRESHOLD FOR NIGERIA: A GUIDE FOR ENVIRONMENTAL POLICY." International Journal of Research - Granthaalayah, 6(9), 178-195. https://doi.org/10.5281/zenodo.1436804.

\section{Introduction}

Recent studies in the area of environmental economics has focused on the role of urban growth in determining greenhouse gasses such as carbon dioxide $\left(\mathrm{CO}_{2}\right)$. Theoretically, this concern has attracted a number of outlooks and propositions. On the one hand, some have seen that rural migration into urban centres, which increases urban population, can also promote urban development and higher energy demand, and consequently a greater emissions of greenhouse gases (see, for example, Martínez-Zarzoso \& Maruotti, 2011). 
It has been argued, on the other hand, that urbanisation has the potential to reduce the concentration of greenhouse gases, especially if the urban areas are densely populated. The latter argument is related to the residential design, particularly those often referred to as 'compact city' (see, for example, Holden \& Norland, 2005). Scholars also, for example, argued that compact cities tend to encourage walking, cycling and promote the use of mass transit against private automobiles, which in turn, can lead to lower energy demand and hence lower emissions of greenhouse gases (see Vandevyvere \& Stremke, 2012; Bodman, 2009). However, there are some scholars who are rather sceptical as to whether urbanisation may have significant influence on energy consumption or pollution emissions (see, for example, O'Neill, et al. 2012; Liddle \& Lung, 2010).

Whatever may be the case, it is commonly assumed that the rate of urbanization may be higher in developing countries compared to already advanced nations. One reason for this could be that least developed countries (LDCs) are still considered to be in their expanding stage with rapid ruralurban migration and development of rural areas into metropolises. Through these processes, Nigeria, like many other developing countries, has recently experienced remarkable increases in the urban population, from about 13 million in 1971 to over 70 million in 2009 (World Bank, 2013).

It is also projected that, by the end of the year 2020, the urban population in Nigeria may likely hit 100 million people (Idowu, 2013). The main determinant of the country's urban population surge is the rural-urban migration with some observed transformation of rural communities into metropolises (see Akinbami \& Fadare, 1997; Idowu, 2013). This process of increasing rural-urban migration and/or structural transformation of rural areas into urban centres tends to increase industrial activities and energy demand, which in turn could exert more pressure on the environmental quality (Poumanyvong \& Kaneko, 2010; Al-mulali et al., 2012).

Studies of the relationships between urbanization and environmental quality are, at best, not unanimous in their submissions. For example, while some scholars argued that the urbanization process is partly responsible for environmental degradation (O'Neill et al. 2010; Martínez-Zarzoso, 2011), others contended rather that it reduces energy consumption and thus lowers pollution emissions (Liddle, 2004; Chen et al., 2008; O'Neill et al., 2012). This therefore justifies the need for further investigation. Research on the anthropogenic impact on environmental quality in Nigeria is still unfolding. This is especially so with regard to the impact of urbanization on the accumulation of environmental pollutants, which is likely to become more intense with the increasing urban population in the country. In addition, the transformation of some rural communities to urban centres would likely have negative feedback regarding the quality of the natural environment.

It is also suggested in the energy literature that, energy consumption is an important determinant of carbon dioxide emissions (see, for example, Katircioğlu, 2014). Population change is also considered as one of the factors that explain the sources of pollution emissions (see MartínezZarzoso, Bengochea-Morancho \& Morales-Lage, 2007; Cole \& Neumayer, 2004). Besides, it has been argued that urban growth and population change have an inextricable link with energy consumption that has greenhouse gas effects (see, Cole \& Neumayer, 2004; Poumanyvong \& Kaneko, 2010; Al-mulali et al., 2012). 
The effects of demographic factors on the environment have been tested within the context of the Stochastic Impacts by Regression on Population, Affluence, and Technology (STIRPAT) framework (see, for example, Dietz \& Rosa, 1997; Cole and Neumayer, 2004; Martínez-Zarzoso \& Maruotti, 2011). The original version of this framework only allows for a monotonic relationship between affluence $(A)$ and environmental impact, but was refined later by York, Rosa, Dietz (2003) to account for the possible non-monotonic relationship, such as including the quadratic term of the affluence $(A)$.

The inclusion of this quadratic term is in line with the well-known environmental Kuznets curve (EKC) framework (Martínez-Zarzoso \& Maruotti, 2011), which assumes an inverted U-shaped relation between the level of environmental pollutants and per capita real income (Grossman \& Krueger, 1995; York et al., 2003). This issue has not been tested specifically with Nigerian data. A clear understanding of the relationships between demographic factors, energy use, and air pollution are necessary to set appropriate policies regarding urban settlements that will be consistent with the country's energy policy, urban design, environmental sustainability, and sustainable economic progress.

In addition, although, a number ecological studies have claimed to find an inverted-U shaped relationship between affluence and environmental quality (most recent examples include studies by Hassan \& Salim, 2015; Aş1c1 \& Acar, 2015; Ibrahim \& Law, 2015 among others), however, a question arose about the accuracy of these claims. Lind and Mehlum (2010) noted that the inclusion of the quadratic form of the affluence fulfils the necessary but may not be a sufficient condition for the existence of an inverted U-shaped relationship. In fact, they argued that of the empirical studies that tested the possible existence of an EKC are practically overwhelmed by uncertainty as they did not appear to be supported by appropriate test $(\mathrm{s})^{1}$. This development may justify or otherwise the reliability of the previous works that claimed the presence of EKC hypothesis. Although, Lind and Mehlum (2010) have proposed a technique to test for appropriate inverted U-shaped relationships, including the environmental Kuznets curve, however, best known to us this test has not been specifically applied to Nigerian data.

In an attempt to close these gaps, we empirically investigate the role of urbanisation, population change and energy consumption within the context of the Stochastic Impacts by Regression on Population, Affluence, and Technology (STIRPAT) framework in Nigeria. Our objectives also include testing for the presence of an inverted U-shaped in the per capita income-environment nexus in the country.

The main contributions of this article are twofold. First, to the best of our knowledge, quantitative long-run relations and the short-run dynamic between urban growth and environmental degradation (pollution emissions) within the context of STIRPAT has not been explicitly investigated in Nigeria. The study further sheds light on whether urban growth in the country a potential has to heighten the already-complex economic problems such as unemployment, inadequate infrastructure and social services (see, Jibrilla, 2010) that need urgent intervention of public policies in the context of human development as well as economic progress.

\footnotetext{
${ }^{1}$ For more theoretical details, see the original article by Lind and Mehlum (2010)
} 
Second, this study is among the first to use the appropriate test of the inverted U-shaped relationship between income and environment as proposed by Lind and Mehlum (2010), particularly using Nigerian data. We believe, findings from this study will provide an additional argument that will help policy makers on how demographic factors should be considered in the future projections of pollution emissions. It is not only relevant for policy makers, but may also be pertinent for academic researchers.

The next section of this study presents the theoretical framework; section 3 describes the empirical models, data used for the study, estimation methods and hypothesis. Section 4 analyses and discusses the estimated results. Then the final section concludes.

\section{The Framework}

In order to examine the impact of urbanization on carbon emissions in Nigeria, this study adapts the well-known IPAT framework, which incorporates key anthropogenic factors that influence environmental quality. This model can be formally represented as (Commoner, Corr \& Stamler, 1971; Ehrlich \& Holdren, 1971)

$I=f(P, A, T)$

where $I$, is the environmental impact, $P$ indicates population, $A$ is affluence or per capita economic activity and $T$ represents technology that determines the environmental impact of goods and services produced in an economy or pollution per unit of economic activity (production and/or consumption).

In this study, we employed the reformulated eqn. (1) by Dietz \& Rosa (1997) into what is termed Stochastic Impacts by Regression on Population, Affluence, and Technology (STIRPAT) to empirically capture the demographic sources of carbon emissions as:

$$
I_{t}=\alpha P_{t}^{\beta} A_{t}^{\lambda} T_{t}^{\gamma} e_{t}
$$

Where $I, P, A$ and $T$ are as previous defined; $\alpha$ denotes the constant term, $\beta, \lambda$ and $\gamma$ represent the elasticity of population, affluence, and technology, respectively; $e$ is the disturbance term assumed to be purely random, and the subscripts $t$ are for the dating of variables, namely in time periods.

Expressing eqn. (2) in logarithms and differentiating it with respect to time yields

$$
\operatorname{InI}_{t}=\alpha+\beta P_{t}+\lambda A_{t}+\gamma T_{t}+e_{t}
$$

Following York et al. (2003) and Martínez-Zarzoso \& Maruotti (2011), the present analysis includes the quadratic term of the affluence (A) to test for the possible existence of an EKC in Nigeria as follows

$$
\operatorname{InI}_{t}=\alpha+\beta P_{t}+\lambda_{1} A_{t}+\lambda_{2} A_{t}+\gamma T_{t}+e_{t}
$$




\section{Empirical Models, Data Estimation Method and Hypothesis}

\section{Model Specification}

Following the modified STIRPAT synthesis and the prediction of the EKC theory, we describe the extended relationship between carbon emissions and urbanization in Nigeria as follows:

$\ln C E_{t}=\alpha_{0}+\alpha_{1} \ln Y_{t}+\alpha_{2} \ln Y_{t}^{2}+\alpha_{3} \ln U B N_{t}+\alpha_{4} \ln P C_{t}+\alpha_{5} \ln E C_{t}+e_{t}$

where $C E$ denotes kilotons of carbon dioxide emissions and $Y$ is GDP per capita (measured in domestic currency), $U B N$ denotes urban population as a share of the total population, $\mathrm{PC}$ represents population change and $E C$ represents energy consumption (proxies by energy use in kilogram of oil equivalent). $\alpha_{0}$ denotes the intercept term, $\alpha_{I}$ represent the long-run elasticity estimates of carbon emissions with respect to regressors identified in model (4) and $\ln$ indicates the natural logarithm transformation. From (4) EKC is supported when $\alpha_{1}$ is significantly positive and $\alpha_{2}$ is significantly negative, and the income turning point is $-\left(\alpha_{1} / 2 \alpha_{2}\right)$.

Based on the synthesis between environmental quality, population, affluence (economic progress) and technology literatures (Dietz \& Rosa, 1997; York et al., 2003; Cole \& Neumayer, 2004; Ibrahim \& Law, 2014), we add energy consumption to capture its potential effect on the pollution emissions in Nigeria. Although, as noted by Cramer in Cole \& Neumayer (2004), there may be a likely response of a population on pollution emissions, perhaps via the health effect, such feedback may not be significantly apparent, particularly for $\mathrm{CO}_{2}$ emissions. Accordingly, we include change in total population to examine its direct scale effect on carbon emissions in our sample country. To examine our fundamental hypothesis that urbanization can be a potential determinant of GHGs, we add urban population growth rate additively to our model. We expect that a higher rate of urbanization can have a positive impact on pollution emissions due to the anticipation that people in urban areas tend to consume more energy than their rural counterparts (see, Cole \& Neumayer, 2004).

\section{Data}

The data used in this study is annual time series: kilotons of carbon dioxide emissions, per capita GDP (measured in domestic currency), energy consumption (proxies by energy use in kilotons of oil equivalent), Urbanization (proxies by urban population as a share of total population and total population for the period of 1971-2013. Carbon dioxide emissions data is obtained from the Emission Database for Global Atmospheric Research (EDGARv4.2) ${ }^{2}$. The GDP data are obtained from the central Bank of Nigeria statistical bulletin (various issues): 1971-2013. All data of the remaining variables have been collected from the online database of the World Bank's world development indicators (WDI, 2015).

\footnotetext{
${ }^{2}$ see Olivier and Janssens-Maenhout (2014) for a description.
} 


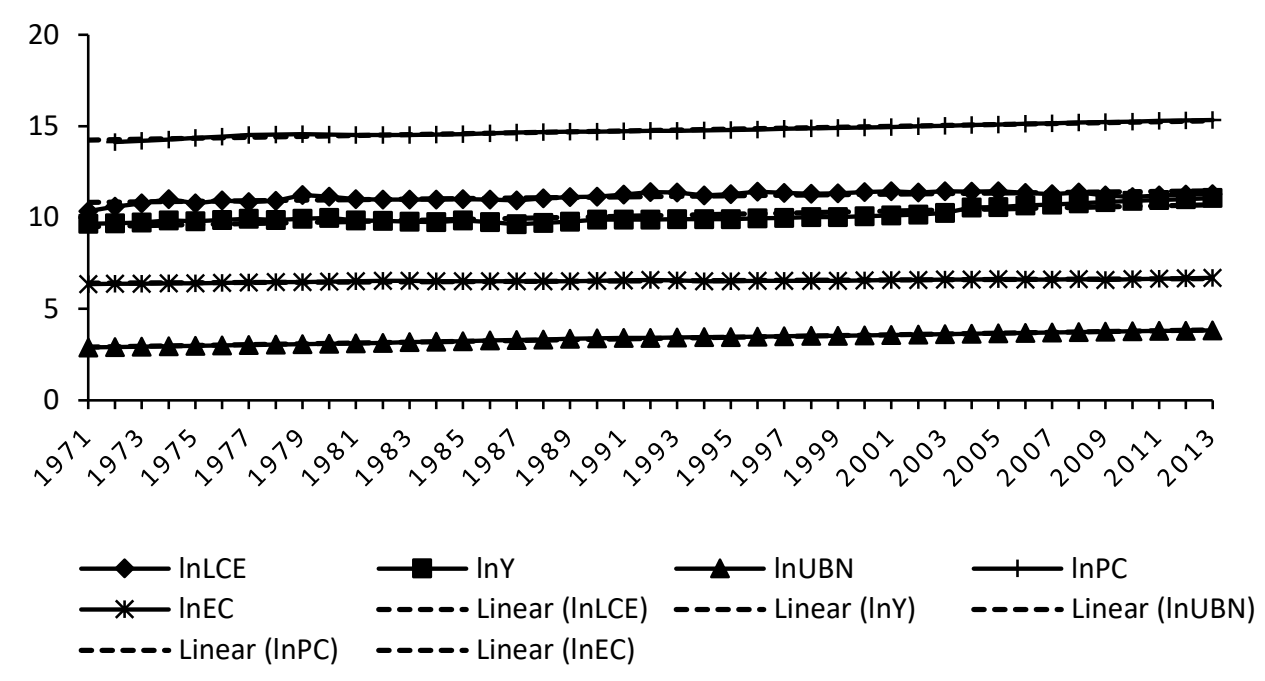

Figure 1: Logarithmic of carbon dioxide emissions, real GDP, urbanisation, population and energy consumption

Figure. 1 illustrates the logarithmic form of carbon dioxide emissions, real GDP, urbanization, population change and energy consumption. It seems that all these variables on average demonstrate common trends. The fact that most of these data follow a common trend tended to suggest that they have potential of strong causal effects. This also indicates that a large portion of the change in $\mathrm{CO} 2$ emissions in Nigeria can be attributed to changes real GDP, urbanization, population change and energy consumption.

\section{Estimation Method}

Given the time series nature and the size of our sample data, we employ autoregressive distributed lag (ARDL) model to estimate eqn. (4). One main advantage of this method is that, it avoids pretesting the order of integration of the individual variables. Thus, it allows estimation of carbon dioxide equation (eqn. 4) regardless of whether its regressors are purely I (0), purely I(1) or are mutually cointegrated (Pesaran, Shin \& Smith, 2001).

Although, by construction, the ARDL technique is robust to the presence of a unit root, as a first step, the analysis will follow the conventional practice, by performing the stationarity tests of the observable individual series using Augmented Dickey-Fuller (ADF), the Philips Perron (PP) and Kwiatkowski-Phillips-Schmidt-Shin (KPSS) unit root tests. Moreover, it is known that these unit root tests may have limited power to reject a unit root, especially if there exist a shift in the integration order of the observable series (see for example, Narayan, 2005). Accordingly, we use the procedures suggested by Zivot and Andrews (Z-A, 1992) and Perron (1997) unit root tests to account for the possible breaks in the series.

If the variables are found to be I (0), I(1) or mixed series, the study will proceed to examine possible long-run relationship among them using the bounds testing cointegration technique proposed by Pesaran and Pesaran (1997) and, Pesaran et al. (2001). This technique involves estimating equation (4) based on the following the following error correction regression (Pesaran \& Pesaran, 1997; Pesaran et al., 2001; Narayan \& Narayan, 2005) 


$$
\begin{aligned}
\Delta \ln C E_{t}= & \delta_{0 C E}+\theta_{1 C E} \ln C E_{t-1}+\theta_{2 C E} \ln Y_{t-1}+\theta_{3 C E} \ln Y_{t-1}^{2}+\theta_{4 C E} \ln U B N_{t-1}+\theta_{5 C E} \ln P C_{t-1} \\
& +\theta_{6 C E} \ln E C_{t-1}+\sum_{i=1}^{p} \alpha_{i C E} \Delta \ln C E_{t-i}+\sum_{i=0}^{p} \beta_{i C E} \Delta \ln Y_{t-i}+\sum_{i=0}^{p} \varphi_{i F D M} \Delta \ln Y_{t-1}^{2} \\
& +\sum_{i=0}^{p} \varpi_{i C E} \Delta \ln U B N_{t-i}+\sum_{i=0}^{p} \lambda_{i C E} \Delta P C_{t-i}+\sum_{i=0}^{p} \gamma_{i C E} \Delta \ln E C_{t-i}+\varepsilon_{1 t}
\end{aligned}
$$

where $\Delta$ denotes the first difference operator, all the remaining variables are as defined in Eqn. (4). The lag orders in equation (5) are chosen based on Akaike Information Criteria (AIC) and the selected model can be estimated using the standard ordinary least squares technique (OLS). F-test statistic is used for the bounds test to examine the presence of a long run relationship among the observable variables of interest. This is done by testing the joint significance of the coefficients of the lagged level variables. So, the null hypothesis in Eqn. (5) is $\left(\mathrm{H}_{0}: \theta_{1 \mathrm{CE}}=\theta_{2 \mathrm{CE}}=\theta_{3 \mathrm{CE}}=\theta_{4 \mathrm{CE}}=\right.$ $\left.\theta_{5 \mathrm{CE}}=\theta_{6 \mathrm{CE}}\right)$ denoted by $\mathrm{F}_{\mathrm{CE}}\left(\mathrm{CE} / \mathrm{Y}, \mathrm{Y}^{2}, \mathrm{UBN}, \mathrm{EC}, \mathrm{PC}\right)$ against the alternative hypothesis $\left(\mathrm{H}_{1}: \theta_{1 \mathrm{CE}}\right.$ $\left.\neq \theta_{2 \mathrm{CE}} \neq \theta_{3 \mathrm{CE}} \neq \theta_{4 \mathrm{CE}} \neq \theta_{5 \mathrm{CE}} \neq \theta_{6 \mathrm{CE}}\right)$.

The asymptotic distribution of the $F$ test that can be used to examine the null hypothesis (of no cointegration) has a nonstandard distribution with two sets of critical values for certain significance levels in Pesaran et al. (2001). While the first set assumes that all the variables are I (0), all variables are assumed to be I(1) in the second set. These critical values, depend on the sample size; the number of explanatory variables; whether the series are I (0) or I(1); and whether the ARDL model contains an intercept and/or a trend (see, e.g. Narayan, 2005). A conclusion of the existence of cointegration can be made if the estimated F-statistics falls outside the upper bounds of I(1), while the conclusion for the nonexistence of cointegration can be made if the computed F-statistics falls below the lower bound of I(0). However, if the calculated F-statistics falls in between the two bounds, then the test become inconclusive.

If the evidence of cointegration is established, the next step is to estimate the long-run coefficients of equation (4) using the ARDL technique. Although, it has been argued that estimates from this approach are robust to endogeneity problems, the robustness of the ARDL results will be assessed further using dynamic OLS (DOLS) methodology, proposed by Stock and Watson (1993). The DOLS approach produces asymptotically efficient and consistent estimations in the existence of endogeneity and autocorrelation problems (see Stock \& Watson, 1993; Esteve \& Requena, 2006). The DOLS estimator of (4) can be expressed as

$$
y_{t}=\alpha_{0}+z_{t}^{\prime} \beta+\sum_{j=-l}^{l} \Omega_{j} \Delta z_{t-j}+v_{t}
$$

where $\beta$ is a ( $\mathrm{K} \times 1)$ vector of the slopes of the regressors, $z_{t}^{\prime}$ is a $(\mathrm{K} \times 1)$ vector of the autoregressive process of the first order difference of the explanatory variables: $z_{t}=z_{t-1}+\varepsilon_{t}$ and, $\varepsilon_{t}$ is the usual error term.

Alongside the estimation of the long run model, the short run dynamics and, Granger causality tests within a vector error correction model (VECM) will also be estimated as follows (Engle \& Granger, 1987; Granger, 1988) 


$$
\begin{aligned}
& \Delta \ln C E_{t}=\alpha_{1}+\sum_{i=1}^{k} \delta_{i i} \Delta \ln C E_{t-i}+\sum_{i=1}^{k} \beta_{1 i} \Delta \ln Y_{t-i}+\sum_{i=1}^{k} \vartheta_{i i} \Delta \ln Y_{t-1}^{2}+\sum_{i=1}^{k} \phi_{1 i} \Delta \ln U B N_{t-i}+\sum_{i=1}^{k} \lambda_{i i} \Delta \ln P C_{t-i}+\sum_{i=1}^{k} \sigma_{1 i} \Delta \ln E C_{t-i}+\eta_{1} E C T_{t-1}+\varepsilon_{t t} \\
& \Delta \ln Y_{t}=\alpha_{2}+\sum_{i=1}^{k} \delta_{2 i} \Delta \ln Y_{t-i}+\sum_{i=1}^{k} \beta_{2 i} \Delta \ln C E_{t-i}+\sum_{i=1}^{k} \vartheta_{i i} \Delta \ln Y_{t-1}^{2}++\sum_{i=1}^{k} \phi_{2 i} \Delta \ln U B N_{t-i}+\sum_{i=1}^{k} \lambda_{2 i} \Delta \ln P C_{t-i}+\sum_{i=1}^{k} \sigma_{2 i} \Delta \ln E C_{t-i}+\eta_{2} E C T_{t-1}+\varepsilon_{2 t} \\
& \Delta \ln Y_{t}^{2}=\alpha_{3}+\sum_{i=1}^{k} \delta_{3 i} \Delta Y_{t-1}^{2}+\sum_{i=1}^{k} \beta_{3 i} \Delta \ln C E_{t-i}+\sum_{i=1}^{k} \vartheta_{3 i} \Delta L Y_{t-i}+\sum_{i=1}^{k} \phi_{3 i} \Delta \ln U B N_{t-i}+\sum_{i=1}^{k} \lambda_{3 i} \Delta \ln P C_{t-i}+\sum_{i=1}^{k} \sigma_{3 i} \Delta \ln E C_{t-i}+\eta_{3} E C T_{t-1}+\varepsilon_{3 t} \\
& \Delta \ln U B N_{t}=\alpha_{4}+\sum_{i=1}^{k} \delta_{4 i} \Delta \ln U B N_{t-i}+\sum_{i=1}^{k} \beta_{4 i} \Delta \ln C E_{t-i} \sum_{i=1}^{k} \vartheta_{4 i t} \Delta L Y_{t-i}+\sum_{i=1}^{k} \phi_{t i} \Delta \ln Y_{t-1}^{2}+\sum_{i=1}^{k} \lambda_{4 i} \Delta \ln P C_{t-i}+\sum_{i=1}^{k} \sigma_{4 i} \Delta \ln E C_{t-i}+\eta_{4} E C T_{t-1}+\varepsilon_{4 t} \\
& \Delta \ln P C_{t}=\alpha_{5}+\sum_{i=1}^{k} \delta_{5 i} \Delta \ln P C_{t-i}+\sum_{i=1}^{k} \beta_{5 i} \Delta \ln C E_{t-i}+\sum_{i=1}^{k} \vartheta_{5 i} \Delta \ln Y_{t-i}+\sum_{i=1}^{k} \phi_{5 i} \Delta \ln Y_{t-1}^{2}+\sum_{i=1}^{k} \lambda_{5 i} \Delta \ln U B N_{t-i}+\sum_{i=1}^{k} \sigma_{5 i} \Delta \ln E C_{t-i}+\eta_{5} E C T_{t-1}+\varepsilon_{5 t} \\
& \Delta \ln E C_{t}=\alpha_{6}+\sum_{i=1}^{k} \delta_{6 i} \Delta \ln E C_{t-i}+\sum_{i=1}^{k} \beta_{6 i} \Delta \ln C E_{t-i}+\sum_{i=1}^{k} \vartheta_{6 i} \Delta \ln Y_{t-i}+\sum_{i=1}^{k} \phi_{6 i} \Delta \ln Y_{t-1}^{2}+\sum_{i=1}^{k} \lambda_{6 i} \Delta \ln U B N_{t-i}+\sum_{i=1}^{k} \sigma_{6 i} \Delta \ln P C_{t-i}+\eta_{6} E C T_{t-1}+\varepsilon_{6 t}
\end{aligned}
$$

where $\Delta$ is the first difference operator, $k$ is the optimal lag length of the differenced variables determined by Schwarz information criteria (AIC), $\varepsilon_{t}$ 's are the disturbance terms assumed to be serially uncorrelated random errors. The $E C T_{t-1}$ term in eqn. (7) represents the cointegrating vector and $\eta_{i}$ is the error correction coefficient that shows by how much any random shock or deviation is adjusted back to the long-run equilibrium. As a rule for any random shock to adjust back to the long-run equilibrium, $\eta_{i}$ has to be negative and statistically significant.

The short-run causality, on the one hand, can be determined by the partial F-statistic in equation (7). If the F-statistic is significantly different from zero, it is an indication of short-run causality running from the right-hand-side variable(s) to the respective left-hand-side (endogenous) variable. For example, if partial F-statistic of the null hypotheses $\beta_{1 i}, \phi_{1 i}, \vartheta_{1 i}, \lambda_{1 i}, \varpi_{1 i}=0$ is rejected, this is an indication of short-run causality running from either one or all of the right-handside variables of eqn. (7a) to carbon emissions in Nigeria. On the other hand, the statistical significance of the error correction term in either of these equations (7), determine the long-run causality between the right- and left-hand side variables.

\section{Analysis of the Estimated Results and Discussion}

\section{Unit Root Tests}

Following conventional practice, we conduct stationarity tests on the series $\mathrm{LCE}_{\mathrm{t}}, \ln \mathrm{Y}_{\mathrm{t}}, \ln \mathrm{Y}_{\mathrm{t}}^{2}$, $\ln \mathrm{UBN}_{\mathrm{t}}, \operatorname{lnPC}_{\mathrm{t}}$ and $\operatorname{lnEC} C_{t}$ to determine their integration properties. These test results are reported in Table 1. The ADF, PP and KPSS unit root tests for the null hypothesis of a unit root in the series is tested against the alternative hypothesis of stationarity. The results of the unit root tests for ADF and PP revealed that, except for carbon dioxide emissions, all the remaining variables are found to be non-stationary at their levels. While for KPSS, which is shown to have high power test compared to ADF and PP (see Hobijn, Franses \& Ooms, 2004; Wang \& Tomek, 2007), only energy consumption and population change variables exhibit unit root properties at levels.

Results from the first differences of all the series suggest that for ADF, only urbanization variable exhibits unit root properties, whilst for the PP tests urbanization and population change are found to be non-stationary at their first differences. Conversely, the KPSS unit root test results reject the null hypothesis of a unit root for all the observable series considered in the present analysis, suggesting that all the variables are integrated of order one, I(1). Nonetheless, the KPSS test tends to have lower power in the presence of break(s) in the dataset (see, for example, Perron, 1989; 
Hobijn et al., 2004). To account for possible structural breaks, we employ Zivot and Andrews (ZA, 1992) and Perron (1997) unit root with endogenous breaks in the dataset. Table 2 shows the results of both Z-A and Perron unit root tests for the variables under consideration.

Table 1: Results of the ADF, PP and KPSS unit root tests

\begin{tabular}{|c|c|c|c|}
\hline & \multicolumn{3}{|c|}{ Levels } \\
\hline Variables & ADF & $\mathbf{P P}$ & KPSS \\
\hline $\operatorname{lnCE} E_{t}$ & $-3.779 * *$ & $-3.773 * *$ & $.175 * *$ \\
\hline $\ln Y_{t}$ & -.304 & -.411 & $.197 * *$ \\
\hline $\ln \mathrm{UBN}_{\mathrm{t}}$ & -2.325 & -1.267 & $.168 * *$ \\
\hline $\operatorname{lnEC_{t}}$ & -2.568 & -2.186 & .116 \\
\hline $\operatorname{lnPC_{t}}$ & -1.558 & -2.851 & .111 \\
\hline \multicolumn{4}{|c|}{ First differences } \\
\hline$\Delta \operatorname{lnCE_{t}}$ & $-6.043 * * *$ & $-7.521 * * *$ & 0.356 \\
\hline$\Delta \ln Y_{t}$ & $-5.354 * * *$ & $-5.461 * * *$ & .397 \\
\hline$\Delta \ln \mathrm{UBN}_{\mathrm{t}}$ & -1.750 & -1.865 & .204 \\
\hline$\Delta \ln \mathrm{EC}_{\mathrm{t}}$ & $-5.482 * * *$ & $-5.481 * * *$ & .129 \\
\hline$\Delta \ln \mathrm{PC}_{\mathrm{t}}$ & $-5.052 * * *$ & -2.382 & .124 \\
\hline
\end{tabular}

Note: $* * *$ and $*$ denote the rejection of the null hypothesis at the $1 \%$ and $10 \%$ significant level, respectively. Lag length for ADF was chosen by Akaike information criterion (AIC). Bandwidth for PP and KPSS using Bartlett Kernel.

As can be observed from Table 2, by taking the structural break(s) into account, the Z-A unit root test results suggest that, only carbon dioxide and urbanisation exhibit stationarity properties, whilst for Perron test, except urbanisation, all the remaining variables exhibit unit root properties. However, the null hypothesis of a unit root is rejected for all the series at their first differences, signifying that they are integrated of order one, I (1).

Table 2: Zivot and Andrews (1992) and Perron (1997) unit root tests with structural breaks

\begin{tabular}{|l|l|l|l|l|}
\hline \multirow{2}{*}{ Variables } & \multicolumn{4}{|c|}{ Levels } \\
\cline { 2 - 5 } & Z-A test & & Perron test & \\
\hline & t-statistic & Break years & t-statistic & Break years \\
\hline $\operatorname{lnCEt}$ & $-5.162 * *$ & 1991 & -5.093 & 1990 \\
\hline $\ln \mathrm{Yt}$ & -3.102 & 1994 & -3.131 & 1993 \\
\hline $\ln \mathrm{UBNt}$ & $-5.359 * * *$ & 1981 & $-5.286 * *$ & 1980 \\
\hline $\operatorname{lnECt}$ & -3.279 & 1994 & -3.024 & 1993 \\
\hline $\ln \mathrm{PCt}$ & -4.252 & 1996 & -5.236 & 1995 \\
\hline First differences & \multicolumn{5}{|l|}{} \\
\hline$\Delta \operatorname{lnCE} \mathrm{t}$ & $-6.554 * * *$ & - & $-7.779 * * *$ & - \\
\hline$\Delta \ln \mathrm{Y}_{\mathrm{t}}$ & $-6.656 * * *$ & - & $-7.244 * * *$ & - \\
\hline$\Delta \ln \mathrm{BNN}_{\mathrm{t}}$ & $-9.292 * * *$ & - & $-9.139 * * *$ & - \\
\hline$\Delta \operatorname{lnEC} \mathrm{t}_{\mathrm{t}}$ & $-6.146 * * *$ & - & $-6.332 * * *$ & - \\
\hline$\Delta \operatorname{lnPC}_{\mathrm{t}}$ & $-6.392 * * *$ & - & $-11.481 * * *$ & - \\
\hline
\end{tabular}

Note: $* * *$ and $* *$ indicate significant at the $1 \%$ and $5 \%$ level. The number of lags is selected based on the AIC. 
Since the unit root tests clearly indicate that all variables are stationary at first difference, that is, I (1); they should therefore appear in the multivariate cointegration test, therefore, cointegration test for Eq. (1) employing ARDL approach is suitable. The ARDL bound test result is given in Table 3:

\section{Cointegration Tests}

Table 3: ADRL bound test results for cointegration relationship

\begin{tabular}{|c|c|c|c|c|c|c|}
\hline \multicolumn{7}{|c|}{ Critical value of the $F$ statistic for the bounds test results with intercept and no time trend } \\
\hline $\mathbf{k}$ & \multicolumn{2}{|c|}{ 99\% level } & \multicolumn{2}{|c|}{$95 \%$ level } & \multicolumn{2}{|c|}{$90 \%$ level } \\
\hline 5 & $\begin{array}{l}\mathrm{I}(0) \\
4.045\end{array}$ & $\begin{array}{l}\text { I (1) } \\
5.898\end{array}$ & $\begin{array}{l}\mathrm{I}(0) \\
2.962\end{array}$ & $\begin{array}{l}\text { I (1) } \\
4.338\end{array}$ & $\begin{array}{l}\text { I }(0) \\
2.483\end{array}$ & $\begin{array}{l}\text { I (1) } \\
3.708\end{array}$ \\
\hline \multicolumn{7}{|l|}{ Computed F-statistics } \\
\hline $\mathrm{F}_{\mathrm{CE}}\left(\mathrm{CE} / \mathrm{Y}, \mathrm{Y}^{2}, \mathrm{UBN}, \mathrm{EC}, \mathrm{PC}\right)$ & 10.21 & & & & & \\
\hline
\end{tabular}

Notes: critical values are from Narayan (2005)

The calculated F-statistic $\mathrm{F}_{\mathrm{CE}}\left(\mathrm{CE} / \mathrm{Y}, \mathrm{Y}^{2}, \mathrm{UBN}, \mathrm{EC}, \mathrm{PC}\right)=10.219$ for model (5) appears to be higher than the critical value (5.898) of the upper bound at the 1\% significance level (Table 3 ). Thus, rejecting the null hypothesis of no cointegration between carbon dioxide emissions and its regressors. The estimated long-run coefficients are presented in Table 4.

\section{Long-Run Elasticities}

Table 4: Estimated long-run coefficients

\begin{tabular}{|l|l|l|l|l|}
\hline Dependent variable: LCE & ARDL & std. errors & DOLS & std. errors \\
\hline Intercept & -53.636 & 12.557 & $-83.717^{\mathrm{a}}$ & 12.252 \\
\hline $\ln \mathrm{Y}_{\mathrm{t}}$ & $10.927^{\mathrm{a}}$ & 2.454 & $16.058^{\mathrm{a}}$ & 2.424 \\
\hline${\ln \mathrm{Y}_{\mathrm{t}}^{2}}^{\mathrm{n}}$ & $-.5345^{\mathrm{a}}$ & .1170 & $-.7873^{\mathrm{a}}$ & .1156 \\
\hline $\operatorname{lnBN}_{\mathrm{t}}$ & .3664 & .2735 & 0.1981 & .2472 \\
\hline $\operatorname{lnPC}_{\mathrm{t}}$ & -.0737 & .2927 & 0.2821 & .2930 \\
\hline InEC $_{\mathrm{t}}$ & $1.400^{\mathrm{b}}$ & .6267 & $1.260^{\mathrm{b}}$ & .5145 \\
\hline Threshold Point & 10.222 & \multicolumn{5}{l|}{} \\
\hline Panel B: Diagnostics Statistics & 10.198 & \\
\hline$\chi_{\text {Norm }}^{2}(2)$ & .6993 & & & \\
\hline$\chi_{\text {LM }}^{2}(1)$ & {$[.7050]$} & & & \\
\hline$\chi_{\text {WT }}^{2}(1)$ & .3358 & & & \\
\hline$\chi_{\text {RESET }}^{2}(1)$ & {$[.5620]$} & & & \\
\hline
\end{tabular}

Notes: ${ }^{\mathrm{a}}$ and ${ }^{\mathrm{b}}$ indicates rejection of hypothesis at the $1 \%$ and 5\% significance level. Notes: ${ }^{\mathrm{a}}$ and ${ }^{\mathrm{b}}$ indicate significance at the $1 \%$ and $5 \%$ levels, respectively. $\chi^{2}$ Norm is the Jarque-Bera test for normality, $\chi_{\text {LM }}^{2}$ is the Serial Correlation LM Test, $\chi^{2}{ }^{\text {wT is }}$ the white hetroskedasticity test, and $\chi^{2}$ RESET is the Ramsey's RESET specification test. The lags used to estimate the ARDL model as well as the lags and leads used to estimate the DOLS model are chosen based on Akaike Information criterion (AIC). 
Table 4 presents estimated results of ARDL and DOLS. From these results we note that the slope coefficient of the DOLS model appears roughly similar to that of ARDL, except that, the coefficient on the $\operatorname{lnPC}_{t}$ bear different sign (in the two models), albeit statistically insignificant. In both models, the coefficient of one of the principal regressors, namely $\ln \mathrm{UBN}_{t}$ seems to be statistically insignificant. Although, both the $\operatorname{lnPC}_{t}$ and $\ln \mathrm{BBN}_{\mathrm{t}}$ variables appear to be not significantly different from zero, it is evident that the long-run elasticity of $\operatorname{lnCE}_{t}$ with respect to the remaining three explanatory variables are found to be statistically significant.

Although it is outside the scope of this study to fully explore the possible reasons for the inability of urbanisation and population change to have significant long-run impact on carbon dioxide emissions, it is possible to suggest a number of causes that may have contributed to this. In the first place, relative to population change, population variation in Nigeria may largely constitute newborns whose consumption pattern could not exert a significant effect on pollution emissions. Second, the insignificance of the urbanization variable seems to suggest that, in the long-run, environmental sustainability in Nigerian is less likely to be significantly influenced by increased urban population, at least as far as can be detected in the data used. It is also possible that most of the per capita energy demand among urban dwellers may not have reached the alarming stage where it will start having a significant effect on greenhouse gas emissions. According to Shaaban and Petinrin (2014), the per capita consumption of energy in Nigeria, particularly electricity consumption is one of the lowest in Africa. However, this finding appears to confirm the results of Cole \& Neumayer (2004) that found similar results and provide evidence contrary to that of Liddle (2004), Martínez-Zarzoso (2011). A likely justification is that our technique deals effectively with unit root, which include accounting for structural break and diagnostic problems and therefore leads to more efficient and reliable estimates.

In support of the EKC hypothesis, the per capita real GDP and the per capita real GDP square are found to be significantly positive and negative respectively. It is noted that the coefficient on the per capita real GDP is reasonably elastic. These relationships are noticeably demonstrated in Figure. 2 in which carbon dioxide emission increases with economic growth and then smoothly decreases after a certain extreme point that is greater than 10 but less than 10.5 (roughly equivalent to those reported in Table 4). For every 1\% increase in the per capita real output, carbon dioxide emissions are increasing by about $10.93 \%$ to $16.06 \%$, whereas the same percent point increase in per capita real GDP square makes pollution to fall roughly $.53 \%$ to $.79 \%$. We have also controlled for energy consumption, which is also found to be a statistically significant determinant of carbon dioxide emissions. A one-point per cent increase in energy use raises carbon dioxide emissions by as much as $1.4 \%$. This finding seems to be consistent with the Nigerian current state of emergent industrial and construction activities, among others which are more energy intensive. 


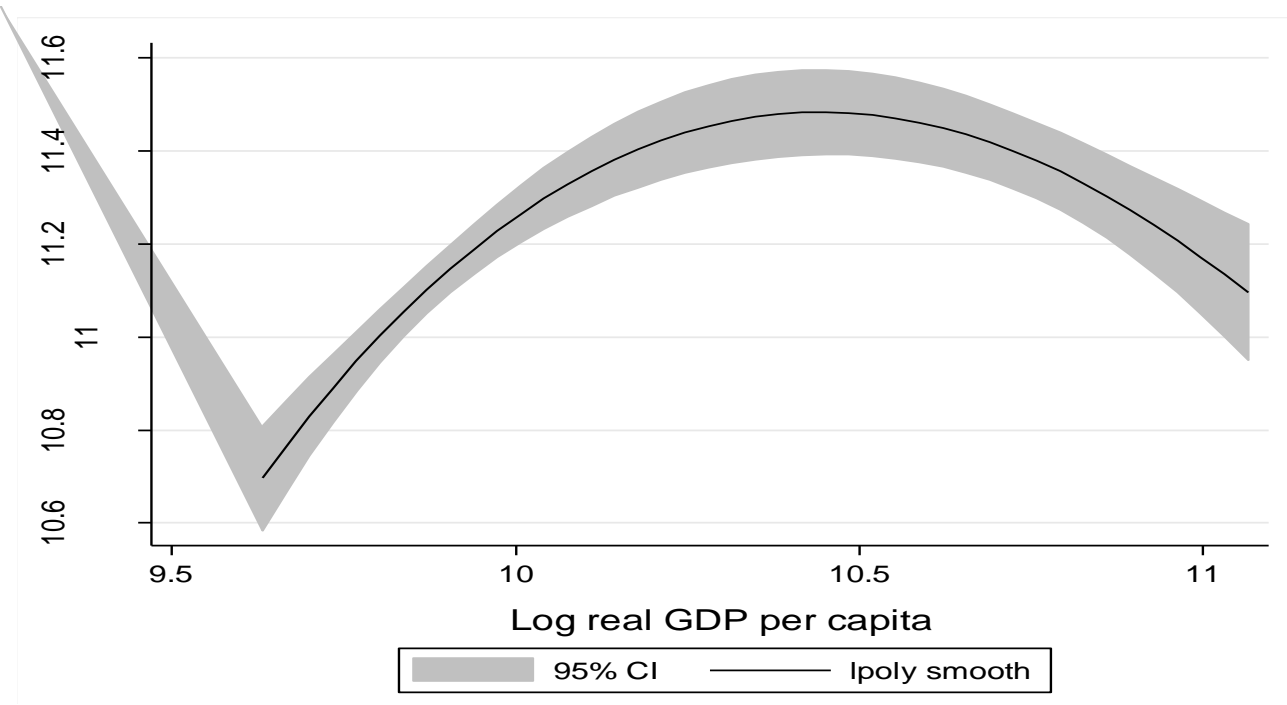

Figure 2: Inverted U-shaped relations between carbon dioxide emissions and economic growth.

To ascertain the robustness of the estimated ARDL model, residual diagnostics of univariate normality, serial correlation and hetroskedasticity tests were performed. As can be observed in Panel B of Table 4, all the test results are in accordance with the classical assumptions, the stability test of recursive residuals using CUSUM and CUSUM Squares (Appendix A) indicate that the estimated ARDL model is free from misspecification, and all the coefficient estimates are relatively stable respectively at the $5 \%$ significance level.

\section{Proper Test of an Inverted U-Shape}

It is worth noting that, although, an inverted U-relationship between per capita income and carbon dioxide emissions is strongly supported by the evidences in both the ARDL and DOLS models reported in tables 4 , however, without a proper test for the existence of the inverted $\mathrm{U}$, our interpretation could be misleading. This suggests that the interpretation of our results of the nonlinearity associated with the EKC in these models should be made with caution.

The next analysis, therefore, focuses on testing empirically the validity of an inverted U shape reported in table 4 as predicted by the composite null hypothesis that the relationship between per capita income and the environment is increasing at the left hand side of the interval and/or is decreasing at the right hand side (i.e. The EKC hypothesis). To do this, we use the test proposed by Lind and Mehlum (2010), which is based on the likelihood ratio test framework developed by Sasabuchi (1980). We also use the Fieller (1954) method to compute the confidence interval for the estimated extreme point, as suggested by Lind and Mehlum (2010). This test can be performed by estimating the following model

$$
\ln L C E=\psi_{0}+\psi_{1} \ln Y_{t}+\psi_{2} \ln Y_{t}^{2}+\mu_{t}
$$

This model involves testing a join hypothesis as

$$
\begin{aligned}
& H_{0}:\left(\psi_{1}+2 \psi_{2} \ln Y_{\min } \leq 0\right) \cup\left(\psi_{1}+2 \psi_{2} \ln Y_{\max } \geq 0\right), \text { against the alternative } \\
& H_{1}:\left(\psi_{1}+2 \psi_{2} \ln Y_{\min }>0\right) \cup\left(\psi_{1}+2 \psi_{2} \ln Y_{\max }<0\right)
\end{aligned}
$$


Table 5: Test of an inverse U-shaped relationship between per capita income and the environment

\begin{tabular}{|l|l|}
\hline Slope at $\ln \mathbf{Y}_{\mathbf{t} \text { min }}$ & $-1.243^{\mathrm{a}}$ \\
& $(-8.153)$ \\
\hline Slope at $\ln \mathbf{Y}_{\mathbf{t} \text { max }}$ & $.9428^{\mathrm{a}}$ \\
& $(5.962)$ \\
\hline Sasabuchi-Lind-Mehlum (SLM) test of inverted U-shape & $5.960^{\mathrm{a}}$ \\
\hline P-value & .0000 \\
\hline Estimated extreme threshold Point & 10.250 \\
\hline $\mathbf{9 9 \%}$ confidence of Fieller interval & {$[9.632,11.066]$} \\
\hline
\end{tabular}

Notes: 'a' indicates statistically significant at $1 \%$. t-statistics in brackets

Table 5 reports the results of testing the presence of an inverted U Shape relationship between economic growth and carbon dioxide emissions in Nigeria. Using the appropriate inverted U test, we observed that while both the upper and lower bound are significantly different from zero, the test for positive slope yield one sided t-values of 5.960, and is significant at the $1 \%$ level. Consequently, the null hypothesis of no inverted U-shape relationship between economic growth and carbon dioxide emissions in Nigeria is rejected, thus validating the results presented in Table 4.

\section{Dynamics and Granger Causality Results}

The dynamic effects and Granger causality results between carbon dioxide emissions and its determinants are presented in Table 5. In the short-run, the results in Equation (7a) indicate that economic growth and urbanization have a positive and statistically significant effect on carbon dioxide emissions, whilst higher economic growth (the real GDP square variable) has a negative and statistically significant effect on emissions. Our short-run results, which show positive and negative effects of income level and higher income level respectively further confirm the EKC hypothesis, while the one which indicates that urbanization increases emissions is similar to longrun findings of Martínez-Zarzoso (2011). In contrast, all the remaining variables do not appear to have a significant effect on emissions in the short-run. In Equation (7b), only carbon dioxide emissions and higher economic growth seem to have significant effects on economic growth, each has a positive effect on it.

As regards to Equation (7c), only carbon dioxide emissions and economic growth appear to have statistically significant effects on the higher income growth. While emissions seem to reduce economic growth, higher economic growth induces its lower level positively. Regarding Equation (7d), carbon dioxide emissions appears to have a positive short-run effect on urbanization, while each of the remaining variables appears to have an insignificant effect. The short-run results in Equations (7e) and (7f), show that, no variable appears to have a statistically significant effect on both population change and energy consumption.

However, judging by the partial F-statistics, the causality test results indicate that, in the short-run, all the variables Granger caused one another. 
Table 5: Error Correction Models and Granger causality tests

\begin{tabular}{|c|c|c|c|c|c|c|}
\hline \multirow{2}{*}{$\begin{array}{l}\text { Independent } \\
\text { variables }\end{array}$} & \multicolumn{6}{|c|}{ Dependent variables } \\
\hline & (7a) $\Delta \operatorname{lnCE} E_{t}$ & $(7 b) \Delta \ln Y_{t}$ & $(7 \mathrm{c}) \Delta \ln \mathrm{Y}_{\mathrm{t}}^{2}$ & $(7 d) \Delta \ln U B N_{t}$ & $(7 \mathrm{e}) \Delta \ln P C_{t}$ & $(7 \mathrm{f}) \Delta \ln E C_{t}$ \\
\hline Constant & $\begin{array}{l}-52.087^{a} \\
(16.734)\end{array}$ & $\begin{array}{l}1.290^{\mathrm{a}} \\
(.4214)\end{array}$ & $\begin{array}{l}-25.936^{\mathrm{a}} \\
(8.539)\end{array}$ & $\begin{array}{l}-1.590 \\
(1.040)\end{array}$ & $\begin{array}{l}2.293 \\
(4.606)\end{array}$ & $\begin{array}{l}3.552 \\
(4.824)\end{array}$ \\
\hline$\Delta \operatorname{lnLCE} E_{t}$ & & $\begin{array}{l}.01156^{\mathrm{a}} \\
(.0041)\end{array}$ & $\begin{array}{l}-.2286^{\mathrm{b}} \\
(.0841)\end{array}$ & $\begin{array}{l}-.0291^{\mathrm{a}} \\
(.0089)\end{array}$ & $\begin{array}{l}-.0545 \\
(.0433)\end{array}$ & $\begin{array}{l}.0668 \\
(.0451)\end{array}$ \\
\hline$\Delta \ln Y_{t}$ & $\begin{array}{l}18.374^{\mathrm{a}} \\
(6.572)\end{array}$ & & $\begin{array}{l}20.217^{\mathrm{a}} \\
(.0965)\end{array}$ & $\begin{array}{l}.0917 \\
(.4137)\end{array}$ & $\begin{array}{l}.4428 \\
(1.770)\end{array}$ & $\begin{array}{l}-.6248 \\
(1.862)\end{array}$ \\
\hline$\Delta \ln Y_{t}^{2}$ & $\begin{array}{l}-.8886^{\mathrm{b}} \\
(.3268)\end{array}$ & $\begin{array}{l}.0494^{\mathrm{a}} \\
(.0002)\end{array}$ & & $\begin{array}{l}-.0039 \\
(.0205)\end{array}$ & $\begin{array}{l}-.0175 \\
(.0876)\end{array}$ & $\begin{array}{l}.0306 \\
(.0921)\end{array}$ \\
\hline$\Delta \ln \mathrm{UBN}_{\mathrm{t}}$ & $\begin{array}{l}9.290^{\mathrm{a}} \\
(2.837)\end{array}$ & $\begin{array}{l}.01844 \\
(.0832)\end{array}$ & $\begin{array}{l}-.3199 \\
(1.683)\end{array}$ & & $\begin{array}{l}-.6172 \\
(.7864)\end{array}$ & $\begin{array}{l}.9198 \\
(.8189)\end{array}$ \\
\hline$\Delta \ln \mathrm{PC}_{\mathrm{t}}$ & $\begin{array}{l}9516 \\
(.7555)\end{array}$ & $\begin{array}{l}.0049 \\
(.0194)\end{array}$ & $\begin{array}{l}-.0786 \\
(.3933)\end{array}$ & $\begin{array}{l}-.0337 \\
(.0429)\end{array}$ & & $\begin{array}{l}-.2034 \\
(.1918)\end{array}$ \\
\hline$\Delta \operatorname{InEC}_{\mathrm{t}}$ & $\begin{array}{l}1.052 \\
(.7108)\end{array}$ & $\begin{array}{l}-.0062 \\
(.0185)\end{array}$ & $\begin{array}{l}.1241 \\
(.3732)\end{array}$ & $\begin{array}{l}.0453 \\
(.0435)\end{array}$ & $\begin{array}{l}-.1835 \\
(.1731)\end{array}$ & \\
\hline$E C T_{t-1}$ & $\begin{array}{l}-.9711^{\mathrm{a}} \\
(.1589)\end{array}$ & $\begin{array}{l}-.2492^{\mathrm{a}} \\
(.0867)\end{array}$ & $\begin{array}{l}-.2389^{a} \\
(.0853)\end{array}$ & $\begin{array}{l}-.0044 \\
(.0160)\end{array}$ & $\begin{array}{l}-.1398^{b} \\
(.0631)\end{array}$ & $\begin{array}{l}-.4224 \\
(.1454)\end{array}$ \\
\hline$F_{6,34}$ & $14.049^{\mathrm{a}}$ & $11848.8^{\mathrm{a}}$ & $11871.3^{\mathrm{a}}$ & $7.568^{\mathrm{a}}$ & $8.352^{\mathrm{a}}$ & $3.318^{b}$ \\
\hline$R^{2}$ & .744 & .999 & .999 & .610 & .633 & .407 \\
\hline$\sigma$ & .0672 & .0017 & .0341 & .0038 & .0161 & .0169 \\
\hline
\end{tabular}

Notes: ${ }^{\mathrm{a}}$ and ${ }^{\mathrm{b}}$ indicate significance at the $1 \%$ and $5 \%$ levels, respectively.

The long-run dynamics, as revealed by the statistical significance of the error correction term, ECT, in Equations (7a, 7b, 7c \& 7e) demonstrate that carbon dioxide emissions, economic growth, higher level of economic growth and population change respond to any deviation from the longrun equilibrium level. It can be noted that, in all the cases, the error correction terms appear to be significantly negative, and the speed of adjustment ranges from $14 \%$ to $97 \%$ per year.

In addition, since the ECT coefficient in each of these Equations (7a, 7b, 7c \& 7e) is statistically significant, it implies a long-run Granger causality running: (i) from income level, higher income level, urbanisation, population change and energy consumption to carbon dioxide emissions, (ii) from carbon dioxide emissions, higher income level, urbanisation, population change and energy consumption to economic growth, (iii) from carbon dioxide emissions, economic growth (income level), urbanisation, population change and energy consumption to higher income level and, (iv) from carbon dioxide emissions, income level, higher income level, urbanisation to population change. Conversely, the insignificance ECT terms of Equations ( $7 \mathrm{~d} \& 7 \mathrm{f}$ ) indicate that there is only unidirectional long-run causality running from urbanisation and energy consumption to carbon dioxide emissions, income level, higher income level and total population change, respectively. In addition, the significance of the ECT terms in Equations (7a \& 7e) indicate a bidirectional long-run causality between carbon dioxide emissions and population change.

It is important to note, that, although, it may seem that the sample size used in this study may be relatively short, it has been shown that both the ARDL and DOLS frameworks applied in the present analysis can produce robust and consistent long-run estimates even in a small sample (see Pesaran \& Shin, 1999; Narayan \& Narayan, 2005). 


\section{Conclusion and Policy Implications}

This study empirically evaluates whether GHGs significantly increase with the rising population and urban growth and whether energy demand/consumption also influences Nigerian contribution of global pollution emissions. Our results, while providing evidence that energy demand leads to increased pollution in the long-run (with no such effect in the short-run), with regards to urbanization, such effect is only found to exist in the short-run. Interestingly, both the short- and long-run affluence-emissions elasticities are found to be positive at lower income levels and negative at higher income growth levels, thus providing robust evidence of an EKC for Nigeria. Population change, which may largely constitute newborns, has no significant effect on pollution emissions.

Our error correction's partial F-statistics, interestingly, found evidence that each of the observable variable considered in the analysis caused one another in the short-run. For long-run Granger causality, based on the statistical significance of the error correction terms, our study found evidence of unidirectional long-run causal running from urbanization and energy consumption to carbon dioxide emissions as well as from urbanization to population change. There is also evidence for bidirectional long-run causality between population change and carbon dioxide emissions.

These findings have important implications in terms of environmental policy perspective. In spite of the perceived negligible African contribution to the global GHGs, our findings suggest that a rising share of global environmental problems will at least be accounted for by certain economic activities in Nigeria. Rising energy demand is one of the established reasons worsened by the fact that Nigeria, like many developing countries, is still in its expanding stage with increasing scale of manufacturing and construction activities. Therefore, we suggest that Nigeria should not be silent in taking measures that would tackle pollutants such as carbon dioxide emissions.

Policy makers such as urban planners should incorporate energy and environmental issues in their future policy targets, which in a way would likely reduce the carbon footprint. Future urban planning and development should encourage and promote recycling and the use of mass transit. Since no single country can produce any commodity with zero emissions, there is a need for unique global environmental policy in which not only African countries should be actively involved in the global environmental policy decisions.

\section{Appendix A}

\section{Plot of Cumulative Sum of Recursive} Residuals

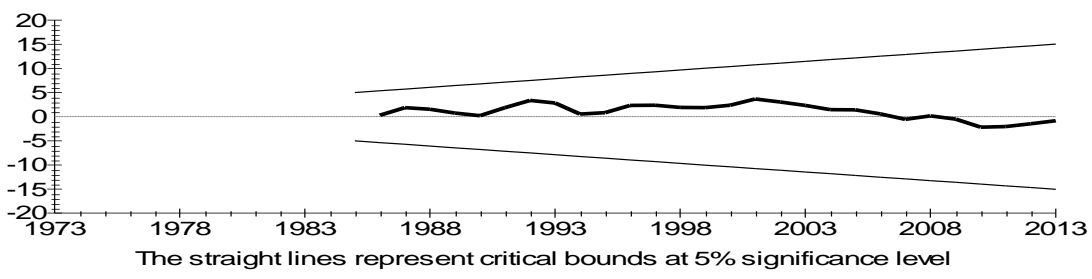



Plot of Cumulative Sum of Squares
of Recursive Residuals

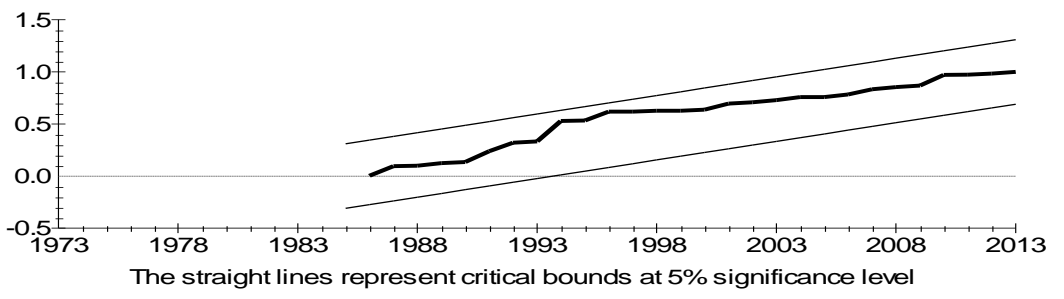

Figure A1: Plots of CUSUM and CUSUMSQ for the estimated VECM model at 5\% significance levels

\section{References}

[1] Ahmad, N., \& Wyckoff, A. (2003). Carbon dioxide emissions embodied in international trade of goods (No. 2003/15). OECD Publishing.

[2] Akinbami, J. F., \& Fadare, S. O. (1997). Strategies for sustainable urban and transport development in Nigeria. Transport Policy, 4(4), 237-245.

[3] Al-mulali, U., Binti Che Sab, C. N., \& Fereidouni, H. G. (2012). Exploring the bi-directional long run relationship between urbanization, energy consumption, and carbon dioxide emission. Energy, 46(1), 156-167.

[4] Ang, J. B. (2008). Economic development, pollutant emissions and energy consumption in Malaysia. Jrnl. Policy Modeling, 30(2), 271-278.

[5] Arthur, J. A. (1991). International labor migration patterns in West Africa. Afr. Studies Review, 34(03), 65-87.

[6] Aşıc1, A. A., \& Acar, S. (2015). Does income growth relocate ecological footprint?. Eco. Indicators. http://dx.doi:10.1016/j.ecolind.2015.10.022

[7] Belloumi, M. (2009). Energy consumption and GDP in Tunisia: cointegration and causality analysis. Energy Policy, 37(7), 2745-2753.

[8] Dodman, D. (2009). Blaming cities for climate change? An analysis of urban greenhouse gas emissions inventories. Environment and Urbanization, 21(1), 185-201.

[9] Chen, H., Jia, B., \& Lau, S. S. Y. (2008). Sustainable urban form for Chinese compact cities: Challenges of a rapid urbanized economy. Habitat Internat., 32(1), 28-40.

[10] Cole, M. A., \& Neumayer, E. (2004). Examining the impact of demographic factors on air pollution. Population and Environment, 26(1), 5-21.

[11] Commoner, B., Corr, M., \& Stamler, P. J. (1971). The causes of pollution. Environment: Science and Policy for Sustainable Devel., 13(3), 2-19.

[12] Dietz, T., \& Rosa, E. A. (1997). Effects of population and affluence on CO2 emissions. Proceedings of the National Academy of Sciences, 94(1), 175-179.

[13] Ehrlich, P. R., \& Holdren, J. P. (1971). Impact of population growth. Sci., 171, 1212-1217

[14] Engle, R. F., \& Granger, C. W. (1987). Co-integration and error correction: representation, estimation, and testing. Econometrica: Jrnl. Econ. Soc., 251-276.

[15] Fieller, E. C. (1954). Some problems in interval estimation. Jrnl. Royal Stat. Soc.. Series B (Methodological), 175-185.

[16] Friedmann, J. (2002). The world city hypothesis. The City: Crit. Concepts Social Sci., 151-163.

[17] Engle, R. F., \& Granger, C. W. (1987). Co-integration and error correction: representation, estimation, and testing. Econometrica: Jrnl. Econ. Soc., 251-276. 
[18] Esteve, V., \& Requena, F. (2006). A cointegration analysis of car advertising and sales data in the presence of structural change. Internat. Jrnl. Econ. Bus., 13(1), 111-128.

[19] Granger, C. W. (1988). Some recent development in a concept of causality. Jrnl. Econ., 39(1), 199211.

[20] Grossman GM, Krueger AB. (1991). Economic growth and the environment. Q. Jrnl. Econ., 110(2), 353-77.

[21] Hassan, K., \& Salim, R. (2015). Population ageing, income growth and CO2 emission: Empirical evidence from high income OECD countries. Jrnl. Econ. Stud., 42(1), 54-67.

[22] Hobijn, B., Franses, P. H., \& Ooms, M. (2004). Generalizations of the KPSS-test for stationarity. Statistica Neerlandica, 58(4), 483-502.

[23] Holden, E., \& Norland, I. T. (2005). Three challenges for the compact city as a sustainable urban form: household consumption of energy and transport in eight residential areas in the greater Oslo region. Urban stud., 42(12), 2145-2166.

[24] Ibrahim, M. H., \& Law, S. H. (2014). Social capital and $\mathrm{CO}_{2}$ emission-output relations: A panel analysis. Renewable and Sustainable Energy Reviews, 29, 528-534.

[25] Ibrahim, M. H., \& Law, S. H. (2015). Institutional Quality and CO2 Emission-Trade Relations: Evidence from Sub-Saharan Africa. S. Afr. Jrnl. Econ.

[26] Idowu, O.O. (2013). Challenges of Urbanization and Urban Growth in Nigeria. Amer. Jrnl. Sustainable Cities and Soc., 1(2), 79-95.

[27] Jibrilla, A.A. (2010). Savings and Domestic Investment in Nigeria: A causal relationship. ADSU Jrnl. Social and Devel. Stud., 4(1), 112-121.

[28] Jiboye, A. D. (2011b). Achieving Sustainable Housing Development in Nigeria: A Critical Challenge to Governance. Internat. Jrnl. of Humanities and Social Sci. 1(9), 121-127.

[29] Jiboye, A. D. (2011c). Ensuring Sustainable Development through an Effective Housing Delivery Process in Nigeria. Afr. Jrnl. Social Sci.. 1(2), 36- 45.

[30] Jiboye, A. D. (2011d). Sustainable Urbanization: Issues and Challenges for Effective Urban Governance in Nigeria. Jrnl. of Sustainable Devel., 4(6), 211-224.

[31] Jiboye, A.D. \& Ogunshakin, L.O. (2011). Urban growth Challenges in Nigeria: Implications for Environmental Sustainability. Brit. Jrnl Humanities and Social Sci., 1(2), 16-27.

[32] Katircioğlu, S. T. (2014). Testing the tourism-induced EKC hypothesis: The case of Singapore. Econ. Modelling, 41, 383-391.

[33] Liddle, B. (2004). Demographic dynamics and per capita environmental impact: using panel regressions and household decompositions to examine population and transport. Population and Environment, 26(1), 23-39.

[34] Liddle, B., \& Lung, S. (2010). Age-structure, urbanization, and climate change in developed countries: revisiting STIRPAT for disaggregated population and consumption-related environmental impacts. Population and Environment, 31(5), 317-343.

[35] Lind, J. T., \& Mehlum, H. (2010). With or Without U? The Appropriate Test for a U-Shaped Relationship*. Oxford Bull. Econ. Statist., 72(1), 109-118.

[36] Lindgren, M. (2012). Total population for countries and territories. Penn World Tables version 3. (PWT 3.0). The data are available at www.gapminder.org/ downloads/ documentation/gd003

[37] Markandya, A., \& Chiabai, A. (2009). Valuing climate change impacts on human health: empirical evidence from the literature. International Journal of Environmental Res. Publ. Health, 6(2), 759786.

[38] Martínez-Zarzoso, I., Bengochea-Morancho, A., \& Morales-Lage, R. (2007). The impact of population on $\mathrm{CO} 2$ emissions: Evidence from European countries. Environmental and Resource Econ., 38(4), 497-512.

[39] Martínez-Zarzoso, I., \& Maruotti, A. (2011). The impact of urbanization on CO2 emissions: Evidence from developing countries. Ecol. Econ., 70(7), 1344-1353.

[40] Narayan, P. K. (2005). The saving and investment nexus for China: evidence from cointegration tests. Appl. Econ., 37(17), 1979-1990. 
[41] Olajire, A. A., Azeez, L., \& Oluyemi, E. A. (2011). Exposure to hazardous air pollutants along Oba Akran road, Lagos-Nigeria. Chemosphere, 84(8), 1044-1051.

[42] Olivier, J.G.J. \& Janssens-Maenhout, G. (2014). CO2 Emissions from Fuel Combustion (Part III). In: CO2 emissions from fuel combustion, 2014 Edition, pp. III.1-III.51. Internat. Energy Agency, Paris.

[43] O'Neill, B. C., Dalton, M., Fuchs, R., Jiang, L., Pachauri, S., \& Zigova, K. (2010). Global demographic trends and future carbon emissions. Proceedings of the National Academy of Sciences, 107(41), 17521-17526.

[44] O'Neill, B. C., Liddle, B., Jiang, L., Smith, K. R., Pachauri, S., Dalton, M., \& Fuchs, R. (2012). Demographic change and carbon dioxide emissions. The Lancet, 380(9837), 157-164.

[45] Patz, J. A., Gibbs, H. K., Foley, J. A., Rogers, J. V., \& Smith, K. R. (2007). Climate change and global health: quantifying a growing ethical crisis. Econ. Health, 4(4), 397-405.

[46] Pesaran, M. H., \& Pesaran, B. (1997). Working with Microfit 4.0: interactive econometric analysis; [Windows version]. Oxford University Press, Oxford.

[47] Pesaran, M. H., Shin, Y., \& Smith, R. J. (2001). Bounds testing approaches to the analysis of level relationships. Jrnl Appl. Econ., 16(3), 289-326.

[48] Poumanyvong, P., \& Kaneko, S. (2010). Does urbanization lead to less energy use and lower CO2 emissions? A cross-country analysis. Ecol. Econ., 70(2), 434-444.

[49] Rezai, A., Foley, D. K., \& Taylor, L. (2012). Global warming and economic externalities. Econ. Theory, 49(2), 329-351.

[50] Sasabuchi, S. (1980). A test of a multivariate normal mean with composite hypotheses determined by linear inequalities. Biometrika, 67(2), 429-439.

[51] Shaaban, M., \& Petinrin, J. O. (2014). Renewable energy potentials in Nigeria: meeting rural energy needs. Renewable and Sustainable Energy Reviews, 29, 72-84.

[52] Stock, J. H., \& Watson, M. W. (1993). A simple estimator of cointegrating vectors in higher order integrated systems. Econometrica: Jrnl. Econometric Soc., 783-820.

[53] United Nations, Department of Economic and Social Affairs, Population Division (2013). World Population Prospects: The 2012 Revision, DVD Edition.

[54] Vandevyvere, H., \& Stremke, S. (2012). Urban planning for a renewable energy future: Methodological challenges and opportunities from a design perspective. Sustainability, 4(6), 13091328.

[55] Wang, D., \& Tomek, W. G. (2007). Commodity prices and unit root tests. Amer. Jrnl. Agric. Econ., 89(4), 873-889.

[56] World Bank group (2013). World Development Indicators 2013. World Bank online databank. The data are available at http://data.worldbank.org/indicator

[57] World Bank group (2014). World Development Indicators 2014. World Bank online databank. The data are available at http://data.worldbank.org/indicator

[58] Yoo, S. H. (2005). Electricity consumption and economic growth: Evidence from Korea. Energy Policy, 33(12), 1627-1632.

[59] York, R., Rosa, E. A., \& Dietz, T. (2003). STIRPAT, IPAT and ImPACT: analytic tools for unpacking the driving forces of environmental impacts. Ecol. Econ. 46(3), 351-365.

[60] Yusuf, K. A., Oluwole, S., Abdusalam, I. O., \& Adewusi, G. R. (2013). Spatial Patterns of Urban Air Pollution in an Industrial Estate, Lagos, Nigeria, Internat. J. Engin. Invent., 2(4), PP: 01-09.

*Corresponding author.

E-mail address: aliyumaiha@ gmail.com 